* Professora Adjunta na graduação e no Mestrado em Direito da Faculdade de Direito da Universidade Federal de Uberlândia(UFU), Coordenadora da Revista da Faculdade de Direito (UFU), Doutora em Direito Político e Econômico pela Universidade Presbiteriana Mackenzie, Doutora em Ciências da Integração da América Latina pela Universidade de São Paulo (PROLAM/USP) e Mestra em Direito Constitucional pela Pontifícia Universidade Católica de São Paulo (PUC/SP) E-mail: julianecaravieri@gmail.com

\section{Revisitando A Dignidade Da Pessoa Humana Em \\ Tempos De Desconstrução De Direitos Sociais Fundamentais (Educação E Trabalho): Contributo De Giovanni Pico Della Mirandola}

\author{
Revisiting The Dignity Of The Human Person In Times \\ Of The Development Of Fundamental Social Rights \\ (EducATION AND LABOR): Contributions Of GiovanNi \\ Pico Della Mirandola
}

Juliane Caravieri Martins*

Como citar: MARTINS, Juliane Caravieri. Revisitando a dignidade da pessoa humana em tempos de desconstrução de direitos sociais fundamentais (educação e trabalho): contributo de Giovanni Pico Della Mirandola. Revista do Direito Público, Londrina, v. 14, n. 3, p. 6486, dez. 2019. DOI: 10.5433/24157-108104-1.2019v14n3p. 64. ISSN: $1980-511 X$

Resumo: Giovanni Pico della Mirandola desenvolveu a ideia de que o homem pode ascender na cadeia das criaturas pelo exercício de suas capacidades intelectuais o que seria a garantia de dignidade da existência humana na vida terrestre, contribuindo para a compreensão da dignidade da pessoa humana nos pactos internacionais, bem como na Constituição brasileira de 1988. O respeito à dignidade da pessoa humana permite a concretização dos direitos fundamentais sociais dos cidadãos, mas, na atualidade brasileira, tem-se visível afronta à sua fundamentalidade, em especial na área da educação e do trabalho. Houve a aprovação da 'reforma' trabalhista (Lei no 13.467/2017) que esgarçou o sistema juslaboral de proteção e a adoção na educação superior pública da figura do docente voluntário. Tais situações promovem profundo retrocesso social no Estado Democrático de Direito mediante a desconstrução de direitos sociais fundamentais dos cidadãos brasileiros.

Palavras-chave: Dignidade humana. Direitos sociais. Cidadania. Trabalho. Educação.

Abstract: Giovanni Pico della Mirandola developed the idea that man can ascend in the chain of creatures by exercising his 
intellectual abilities which would guarantee the dignity of human existence in his earthly life. This school of thought contributed to the understanding of the dignity of the human person in international agreements, as well as in the Brazilian Constitution of 1988. Moreover, respecting the dignity of the human person is the first step in guaranteeing other fundamental social rights, but, in the Brazilian context, there is a visible confrontation in its importance, especially in the area of education and labor. Furthermore, the approval of the Brazilian labor reform (Law n. 13.467/2017) shattered the labor protection system and unfortunately created the institute of "volunteer professors" in higher education. Such situations promote a deep social inequality in Brazil's Democratic State of Law through the deconstruction of fundamental social rights.

Keywords: Human dignity; social rights; citizenship; labor; education. 


\section{INTRODUÇÃO}

O ser humano, enquanto ser social e político, sempre procurou estabelecer regras de convivência em comunidade, objetivando a harmonia na coexistência com seus semelhantes desde tempos remotos da civilização. $\mathrm{O}$ direito é, pois, originário da própria natureza do homem que "sentiu" a necessidade de conversão dos anseios sociais em normas coercitivas, superando a época em que a força física prevalecia na vida em comunidade.

Remonta ao período axial, entre aos anos de 600 a.C a 480 a.C., as primeiras reflexões do homem sobre si mesmo e a tentativa de explicar a dignidade humana, destacando-se como Zaratrusta na Pérsia, Buda na Índia, Lao-Tsé e Confúcio na China, Pitágoras na Grécia e DêuteroIsaías $^{1}$ em Israel os quais difundiram ideias acerca da compreensão do homem no mundo.

Após o período axial, “[...] o ser humano passa a ser considerado, em sua igualdade essencial, como ser dotado de liberdade e razão ou costumes sociais. Lançavam-se, assim, os fundamentos intelectuais para a compreensão da pessoa humana e para a afirmação da existência de direitos universais, porque a ela inerentes." (COMPARATO, 2007a, p. 11-120). Entretanto, foram necessários vinte e cinco séculos para que se positivasse num documento escrito, de cunho universal, a Declaração Universal dos Direitos Humanos de 1948, que todas as pessoas nasciam livres e iguais em dignidade e direitos (art. I).

No decorrer da história e da civilização, evoluiu a concepção da dignidade da pessoa humana como indissociável do direito, em especial no âmbito dos direitos humanos e fundamentais, pois ela não esteve sempre presente nas leis escritas para todos os povos e os Estados. Esta concepção foi construída e reconstruída permanentemente ao longo do tempo a partir do convívio em comunidade, pois “o valor da pessoa humana enquanto 'valor-fonte' da ordem de vida em sociedade encontra a sua expressão jurídica nos direitos fundamentais do homem." (LAFER, 2006, p. 20).

Então, a dignidade da pessoa humana despontou, após o término da Segunda Guerra Mundial, como princípio e valor de maior importância nos Estados Democráticos de Direito, sendo a referência ético-jurídica a inspirar o direito construído e positivado, norteando a interpretação e aplicação das normas em nível interno e internacional. Tal concepção representou uma resposta mundial aos regimes totalitários, em especial nazista e fascista, que praticaram atrocidades contra a pessoa humana em função das diferenças étnicas, culturais, religiosas etc. Porém, a "reconstrução" dos direitos humanos, iniciada no pós-1945, encontra-se atualmente ameaçada apesar das declarações, dos pactos e dos organismos internacionais existentes em sua defesa.

Sob esse prisma, é de suma importância revisitar a concepção de dignidade da pessoa humana à luz do pensamento de Giovanni Pico della Mirandola (1463-1494) exarado no Discurso sobre a Dignidade do Homem (Oratio de Hominis Dignitate), sobretudo nos tempos atuais em

1 O livro de Isaías abrange um período de quase trezentos anos, assim, nem todos os capítulos poderiam ter sido escritos pela mesma pessoa. A maioria dos estudiosos da Bíblia acredita que os capítulos 01 a 39 foram escritos pelo profeta chamado Proto-Isaías, enquanto os capítulos 40 a 55 teriam sido escritos por profetas anônimos que viveram nos séculos seguintes, sendo chamados de Dêutero-Isaías (PROFETAS..., 2006, p. 35). 
que se verifica a reiterada desconstrução dos direitos sociais fundamentais no Brasil, apesar da Constituição de 1988 possuir significativo elenco desses direitos os quais integram o patrimônio jurídico dos cidadãos brasileiros.

A realidade brasileira contemporânea se mostra distante da efetivação dos preceitos constitucionais, sobretudo na educação e no trabalho que estão entre os direitos sociais fundamentais (art. $6^{\circ}$ da CF), pois o governo federal - amparado em diretrizes neoliberais disseminadas a partir do Consenso de Washington (1989) - está implementando ações que promovem significativo retrocesso social. Dentre tais ações, está a aprovação da reforma trabalhista pela Lei nº 13.467/2017 que esgarçou o sistema juslaboral de proteção aos trabalhadores e a adoção na educação superior pública, principalmente nas universidades federais, da figura do docente voluntário, situações que aprofundarão as desigualdades sociais e econômicas nos anos vindouros da nação brasileira.

Assim, o presente estudo dividiu-se em três partes. Primeiramente, buscou-se apreender a concepção de dignidade da pessoa humana no pensamento de Giovanni Pico della Mirandola. A seguir, centrou-se na análise da dignidade humana como princípio e valor constitucional. Por fim, apreendeu-se a fundamentalidade dos direitos sociais sob influência da concepção de dignidade de Pico della Mirandola e a vedação ao retrocesso social na Constituição brasileira de 1988, enfocando criticamente o significado da 'reforma' trabalhista (Lei no 13.467/2017) e a adoção na educação superior pública da figura do docente voluntário, principalmente nas universidades federais.

Como metodologia científica, a pesquisa utilizou os seguintes métodos: dialético (contraposição entre tese e antítese) e histórico-sociológico (investigação de fatos, processos e instituições ao longo do tempo). Quanto à técnica de pesquisa, utilizou-se a bibliográficodoutrinária, enfocando interdisciplinarmente o Direito Constitucional e os Direitos Humanos.

Desse modo, com fundamento nas lições de Giovanni Pico dela Mirandola, a pesquisa tentou, na medida do possível, refletir acerca dos direitos sociais fundamentais inspirados nessa concepção jusfilosófica de dignidade humana, sobretudo em tempos sombrios de globalização neoliberal excludente ora vivenciados.

\section{FUNDAMENTOS JUSFILOSÓFICOS DA DIGNIDADE DA PESSOA HUMANA POR GIOVANNI PICO DELLA MIRANDOLA}

Giovanni Pico della Mirandola, filósofo humanista, nasceu em Mirandola, próximo a Modena (Itália), em 24 de fevereiro de 1463, morrendo aos trinta e um anos de idade em Florença, em 17 de novembro de 1494, ficando conhecido como "a fênix dos gênios", em função da amplitude e precocidade de seu saber. Era filho de Gian Francesco I e Giulia Boiardo, Conde e Condessa de Concordia e de Mirandola, e impressionava, desde a infância, por suas faculdades intelectuais, dedicando-se aos estudos. Sua mãe destinou-o à vida eclesiástica e, em 1477, foi enviado, aos quatorze anos, para a Universidade de Bolonha, no intuito de estudar Direito Canônico. Entretanto, após dois anos de estudos jurídicos, descobriu que não estava seguindo o caminho adequado (LOIA, 2006). 
Entre 1479 e 1480, Pico della Mirandola realizou o curso de Letras em Ferrara, sob a orientação de Batista Guarino de Verona e, posteriormente, instalou-se em Pádua (1481-1482), onde se dedicou aos estudos de Filosofia e Teologia que, no seu entender, representariam conhecimentos mais aprofundados da realidade humana. Nesse período, resgatou, em seus estudos, as ideias de Platão, Aristóteles, São Tomás de Aquino e outros, aprofundando seus conhecimentos nas línguas latina e grega, tendo praticado também o árabe e o hebraico. Ele passou, ainda, sete anos viajando pela Itália e França, estudando nas principais faculdades em Ferrara, Pádua, Mântua, Pavia, Florença e Paris. O seu objetivo principal era a conciliação entre a religião e a filosofia (LOIA, 2006).

A partir de 1484, Pico della Mirandola ingressou na Academia Florentina e, acolhendo os ensinamentos de seu mestre Marcílio Ficino, alterou suas concepções do aristotelismo paduano para o platonismo florentino, sendo que estas últimas o seguirão no seu pensamento filosófico. De 1485 a 1486, dirigiu-se a Paris para aperfeiçoar seus conhecimentos em Filosofia e línguas orientais e depois retornou à Itália onde aprofundou seus estudos na Cabala e no hebraico com dois mestres judeus: Elias de Mendigo e Flávio Mitríades (LOIA, 2006).

Retornando da França à Itália, em 1486, em Fratta, Pico della Mirandola, com somente vinte e três anos, redigiu a sua obra mais original, sob o prisma do contexto histórico-social da época, propondo-se a reunir neste trabalho todo o conhecimento que havia adquirido até aquele momento. Desse modo, em dezembro de 1486, tornou pública a polêmica obra "Novecentas Teses" ou "Conclusões" (Conclusiones nongentae in omni genere scientiarum) ao fixar o elenco das Teses nas portas de Roma (antigo costume acadêmico em voga na vida universitária da época), lançando, assim, aos juízes da banca examinadora o desafio de avaliá-las e ficou aguardando por um ano o resultado do julgamento. O Discurso sobre a Dignidade do Homem (Oratio de Hominis Dignitate), escrito em latim, não foi concebida como uma obra autônoma, mas representou uma introdução às "Novecentas Teses" (LOIA, 2006).

Entretanto, treze das Teses não foram aprovadas, sendo consideradas heréticas e proibidas de divulgação, justamente aquelas integrantes da segunda parte do trabalho em que Pico della Mirandola exprimia as suas opiniões. Assim, ele apresentou sua resposta aos examinadores da banca, intitulada Apologia (1487), contrária à desaprovação de suas treze teses, mas não obteve sucesso, sendo condenado à prisão pelo Santo Ofício da Inquisição. Utilizando-se de suas influências políticas, em 1488, Giovanni Pico della Mirandola conseguiu ser posto em liberdade, retornou à Itália, sob a proteção de Lourenço, o Magnífico ${ }^{2}$, e refugiou-se em Florença onde passou a viver de modo singelo e austero, renunciando aos seus bens materiais e dedicando-se aos estudos religiosos até a sua morte em 1496. Giovanni Francesco Pico della Mirandola, seu sobrinho, publicou a Oratio de Hominis Dignitate, postumamente à morte do tio, precedida de uma biografia onde tentou reabilitar a sua figura, maculada pela Santa Inquisição (LOIA, 2006).

A Oratio está dividida em duas partes: a primeira analisa a questão da natureza e da

2 Lourenço de Médici (1449-1492), chamado o Magnífico, foi o governante de Florença (Itália) no período renascentista do quattrocento. 
dignidade do homem, justificando o estudo da filosofia como instrumento para a concretização dessa natureza; a segunda parte, por sua vez, representa uma justificação da existência de contraditórias posições filosóficas e religiosas acerca dessa natureza e dignidade, sendo que, no presente estudo, serão realizadas considerações acerca somente da primeira parte da obra.

Na Oratio de Hominis Dignitate 3 é nítida a influência humanista e renascentista no pensamento de Giovanni Pico della Mirandola, pois a temática da obra é inovadora para a época porque, até aquele momento, os filósofos e os pensadores, influenciados pela Idade Medieval, estavam mais direcionados a temas relacionados às questões de cunho religioso não se preocupando em explicar a natureza humana.

Giovanni Pico della Mirandola imaginou que Deus, ao completar a sua obra, tendo criado todas as criaturas, povoando o mundo terrestre com animais de toda espécie e o mundo celeste com espíritos puros, acabou gerando outra criatura - um ser consciente - que fosse capaz de apreciar a sua criação divina, amando sua beleza e admirando a sua vastidão. Assim, Deus criou o homem que, ao contrário das demais criaturas, não possuía um lugar próprio e específico no âmbito da criação e, para compensar essa "inadequação" (o homem seria naturalmente incompleto), Deus decidiu, em sua infinita sabedoria, que ao homem fosse conferida a capacidade de apreender sobre si mesmo, sobre a natureza e os demais animais.

Então, Pico della Mirandola desenvolveu a ideia de que o homem poderia ascender na cadeia das criaturas pelo exercício de suas capacidades intelectuais o que seria a garantia de dignidade da existência humana na vida terrestre. Assim, a própria dignidade humana residiria na afirmação de que somente os seres humanos poderiam mudar a si mesmos pelo seu livre arbítrio, possuindo a vida que almejariam.

Para o Conte di Concórdia e della Mirandola, o homem é um ser entre dois mundos - o mundo celeste que é superior e o mundo terrestre, inferior - e entre dois tempos -, a finitude e a eternidade - mas é também um ser dotado de corpo, de sensibilidade e de razão e, como suprema e mais perfeita criatura de Deus, é portador de uma "natureza indefinida" que necessita de ser concretizada, isto é, realizada de acordo com esta sua essência. Neste sentido, o homem é livre e responsável perante a vida que tem e a vida que quer ter, visto que esta é obra sua. Pode-se, assim, falar de uma natureza animal, uma natureza propriamente humana e uma natureza divina que coexistem no homem visto, neste sentido, como um microcosmos de toda a realidade (LOIA, 2006, p. XLVI).

$\mathrm{Na}$ Oratio, a partir de complexos argumentos, raciocínios e citações de livros sagrados (nem todos cristãos), Pico della Mirandola pretendeu situar o homem como um ser digno que, do ponto de vista de sua singularidade e perfectibilidade, seria superior aos querubins e serafins oriundos diretamente de Deus. No transcorrer desta obra, que elogiava o homem, ele demonstrou

3 Esta obra apresenta o profundo conhecimento do autor acerca dos filósofos gregos, cristãos, judeus e árabes, além de conter referências a metafísica, antropologia, religião e magia. Esses estudos, fortemente influenciados por Platão, levaram Giovanni Pico della Mirandola a tentar conciliar a filosofia clássica, especialmente a grega, com o cristianismo, questionando o lugar do homem no mundo. Logo, o homem é concebido como sendo de diferentes ordens do universo: a divina, a celeste e a terrena, o que corresponderia ao corpo, a alma e ao espírito humanos. 
o quanto Deus foi sublime e admirável na criação da espécie humana e o quanto caberia ao próprio ser humano manter a sua dignidade e ampliar a sua condição de perfectibilidade como forma de glorificar a Deus.

Assim, o homem possui a felicidade de ser livre para escolher seu caminho, obter o que deseja e ser aquilo o que quer, podendo, inclusive, ascender na cadeia evolutiva, sendo anjo e filho de Deus. Mirandola (2006, p. 57 e p. 59) viu o homem como animal celeste de natureza vária, multiforme e mutável, semelhante a um camaleão:

Ó suma liberalidade de Deus pai, ó suma e admirável felicidade do homem! ao qual é concedido obter o que deseja, ser aquilo que quer. As bestas, no momento em que nascem, trazem consigo do ventre materno, como diz Lucílio, tudo aquilo que depois terão. Os espíritos superiores ou desde o princípio, ou pouco depois, foram o que serão eternamente. Ao homem nascente o Pai conferiu sementes de toda a espécie e germes de toda a vida, e segundo a maneira de cada um os cultivar assim estes nele crescerão e darão os seus frutos. Se vegetais, tornar-se-á planta. Se sensíveis, será besta. Se racionais, elevar-se-á a animal celeste. Se intelectuais, será anjo e filho de Deus, e se, não contente com a sorte de nenhuma criatura, se recolher no centro da sua unidade, tornado espírito uno com Deus, na solitária caligem do Pai, aquele que foi posto sobre todas as coisas estará sobre todas as coisas. Quem não admirará este nosso camaleão? [...] Daí o dito caldaico de que o homem é animal de natureza vária, multiforme e mutável.

O Conde della Mirandola pregou o homem como milagre da criação divina, de modo que, graças à possibilidade de ser tudo o que quisesse, ele se tornaria o centro do universo, a centralidade do mundo, o mediador das realidades terrena, celeste e divina. Tais preceitos lançaram as raízes da visão antropocêntrica que influenciaria a filosofia e as ciências no período após o Renascimento. Portanto, na condição de representante do humanismo renascentista, Mirandola (2006, p. 55-57) evidenciou a pessoa humana enquanto ser terreno e celeste, ou seja, na condição de sujeito central do mundo:

Já o Sumo Pai, Deus arquitecto, tinha construído segundo leis de arcana sabedoria este lugar do mundo como nós o vemos, augustíssimo templo da divindade. Tinha embelezado a zona superceleste com inteligências, avivado os globos etéreos com almas eternas, povoado com uma multidão de animais de toda a espécie as partes vis e fermentantes do mundo inferior. Mas, consumada a obra, o Artifice desejava que houvesse alguém capaz de compreender a razão de uma obra tão grande, que amasse a beleza e admirasse a sua grandeza. Por isso, uma vez tudo realizado, como Moisés e Timeu atestam, pensou por último criar o homem. [...] Assim, tomou o homem como obra de natureza indefinida e, colocando-o no meio do mundo, falou-lhe deste modo: "Ó Adão, não te demos nem um lugar determinado, nem um aspecto que te seja próprio, nem tarefa alguma especifica, a fim de que obtenhas e possuas aquele lugar, aquele aspecto, aquela tarefa que tu seguramente desejares, tudo segundo o teu parecer e a tua decisão. A natureza bem definida dos outros seres é refreada por leis por nós prescritas. Tu, pelo contrário, não constrangido por nenhuma limitação, determiná-la-ás para ti, 
segundo o teu arbítrio, a cujo poder te entreguei. Coloquei-te no meio do mundo para que daí possas olhar melhor tudo o que há no mundo. Não te fizemos celeste nem terreno, nem mortal nem imortal, a fim de que tu, árbitro e soberano artifice de ti mesmo, te plamasse e te informasses, na forma que tivesses seguramente escolhido [...] (grifo nosso).

Revela-se, assim, a valorização do homem como soberano de si mesmo, orientado por sua razão e livre arbítrio, como a centralidade do mundo, superior às outras criaturas, sendo a sua dignidade condição intrínseca da sua natureza de "camaleão", multiforme e mutável. As considerações deste filósofo renascentista contribuíram para a consolidação da visão antropocêntrica da relação homem e mundo. Entretanto, a partir do século XIX, com o desenvolvimento do capitalismo industrial e financeiro, houve a agudização do individualismo como referencial adotado nas sociedades, proporcionando a mitigação da dignidade da pessoa humana.

É notório nas declarações de direitos elaboradas após o século XIX e influenciadas pelo Iluminismo, o "abandono" da referência ao homem como criatura divina e, consequentemente, da sua dignidade como intrinsecamente relacionada a um poder divino e superior, sendo enfatizada a visão do homem como ser individual e singular, dotado de racionalidade e de igualdade perante o direito $^{4}$, resgatando-se concepções da filosofia grega.

Historicamente, o fundamento da dignidade humana justificou-se a partir de três aspectos complementares e não excludentes: o religioso, o filosófico e o científico. No âmbito religioso, o monoteísmo realçou a dignidade da pessoa humana, destacando-se, no relato bíblico da Gênesis, que na criação do mundo Deus criou primeiramente os animais mais simples, sobrepondoos uns aos outros, até a criação final do ser mais complexo: o homem, criado à sua imagem e semelhança (imago Dei), estando situado entre o Céu e a Terra e possuindo, a um só tempo, natureza divina e terrena. No âmbito da antropologia filosófica, a dignidade humana está relacionada à condição do homem como animal racional e à sua consciência, individual e coletiva, dessa questão única no mundo. [...] Finalmente, sob o aspecto científico, a dignidade humana está relacionada à condição do homem como espécie que ocupa o ápice do processo evolutivo, oriundo da transformação dos hominídeos primitivos na espécie homo sapiens. Ademais, o homem, ao atingir esse ponto na cadeia evolutiva, com o desenvolvimento da ciência, em especial a genética, passa a interferir não somente em seu entorno, mas se volta para o próprio corpo humano no intuito de manipulá-lo a seu bel prazer, transformando-se de criatura em criador (COMPARATO, 2007b, p. 481-483).

Portanto, é notória a difícil tarefa de estabelecer algum conceito jusfilosófico para a dignidade da pessoa humana ante as constantes alterações ao longo da história da compreensão acerca da natureza humana, sendo importante, nos dias atuais, a contribuição de Giovanni Pico della Mirandola na seara dos direitos sociais fundamentais.

4 Nesse sentido, foram elaboradas a Declaração de Independência dos Estados Unidos da América de 1776, a Declaração Francesa dos Direitos do Homem e do Cidadão de 1789 e a Declaração Universal dos Direitos Humanos de 1948. 


\section{A DIGNIDADE HUMANA COMO PRINCÍPIO E VALOR CONSTITUCIONAL}

No âmbito do humanismo renascentista do século XV, demostrou-se fundamental o pensamento de Giovanni Pico della Mirandola para a concepção de dignidade humana a fim de apreender o homem como o milagre da criação divina, guiando-se por seu livre arbítrio, sendo semeada a visão antropocêntrica do ser humano na condição de sujeito central do mundo, da polis e da communitas. Após a segunda metade do século XX, a dignidade humana foi erigida ao status de princípio e valor de maior importância presente nas Constituições dos Estados Democráticos, sendo a referência ético-jurídica a nortear a interpretação e a aplicação do direito, especialmente os direitos humanos e fundamentais.

Mas, afinal, como se pode conceituar a dignidade da pessoa humana? Segundo o Vocabulário Jurídico, a dignidade deriva do latim dignitas (virtude, honra, consideração), representando a qualidade moral de uma pessoa e servindo de base ao próprio respeito em que é compreendida. Além disso, é entendida como “[...] o próprio procedimento da pessoa, pelo qual se faz merecedor do conceito público. Mas, em sentido jurídico, também se entende como a distinção ou honraria conferida a uma pessoa, consistente em cargo ou título de alta graduação." (SILVA, 2005, p. 458).

Abbagnano (2007, p. 326), quando se refere à dignidade, faz menção direta a Immanuel Kant na segunda formulação do Imperativo Categórico, sistematizado na "Fundamentação da Metafísica dos Costumes", o qual dispõe: "age de tal forma que trates a humanidade, tanto na tua pessoa como na pessoa de qualquer outro, sempre também como um fim e nunca unicamente como um meio". Portanto, todo o ser humano deve ser visto como um fim em si mesmo, possuidor de um valor (a dignidade) e não como mercadoria descartável no mundo capitalista.

Portanto, segundo Kant (2008), "tudo possui ou um preço ou uma dignidade. Aquilo que tem preço pode ser substituído por algo equivalente; por outro lado, o que se acha acima de todo preço e, portanto, não admite nada equivalente, encerra uma dignidade". Em sentido semelhante, Garcia (2004, p. 211) pontua que "a dignidade da pessoa humana corresponde à compreensão do ser humano na sua integridade física e psíquica, como autodeterminação consciente, garantida moral e juridicamente". Por fim, Sarlet (2007, p. 62) formula conceito de cunho jusfilosófico para a compreensão da dignidade humana, a saber:

[...] além de reunir a dupla perspectiva ontológica e instrumental referida, procura destacar tanto a sua necessária faceta intersubjetiva e, portanto, relacional, quanto a sua dimensão simultaneamente negativa (defensiva) e positiva (prestacional). Assim sendo, temos por dignidade da pessoa humana a qualidade intrinseca e distintiva reconhecida em cada ser humano que o faz merecedor do mesmo respeito e consideração por parte do Estado e da comunidade, implicando, neste sentido, um complexo de direitos e deveres fundamentais que assegurem a pessoa tanto contra todo e qualquer ato de cunho degradante e desumano, como venham a lhe garantir as condições existenciais mínimas para uma vida saudável, além 
de propiciar e promover sua participação ativa e co-responsável nos destinos da própria existência e da vida em comunhão com os demais seres humanos. (grifo do autor).

É nessa direção jusfilosófica que deve caminhar a compreensão da dignidade da pessoa humana e, consequentemente, a dignidade do trabalhador no âmbito dos Estados Democráticos, sendo protegida integralmente pelo direito. A dignidade da pessoa humana, incluindo o homem-trabalhador, é inerente à própria condição humana e não deve ser mitigada, pois, nesse caso, o ser humano - embora ser único e insubstituível - passará a ser tratado como mercadoria sujeita às trocas no sistema capitalista, contrariando a segunda formulação do Imperativo Categórico de Immanuel Kant.

Essa acepção da dignidade da pessoa humana, como princípio e valor constitucional, foi incorporada nas Constituições de diversos países, destacando-se na Europa: Alemanha (art. $1^{\circ}$, I), Grécia (art. $2^{\circ}$, I), Irlanda (Preâmbulo), Itália (art. $3^{\circ}$ ), Espanha (Preâmbulo e art. $\left.10, \S 1^{\circ}\right)$ e Portugal $\left(\operatorname{art.~} 1^{\circ}\right)$. Na América do Sul, a dignidade da pessoa humana está presente na Constituição do Paraguai (Preâmbulo), da Venezuela (Preâmbulo), do Peru (art. $4^{\circ}$ ), da Bolívia (art. $6^{\circ}$, II) e do Chile (art. $1^{\circ}$ ).

No Brasil, na Constituição de 1988, chamada de Constituição Cidadã, a dignidade humana foi consagrada ao longo de todo o texto constitucional, com ênfase no art. $1^{\circ}$, inciso III como fundamento do Estado Democrático de Direito; como finalidade precípua da ordem econômica (art. 170) e da ordem social (art. 193); como fundamento da família e do planejamento familiar (art. 226, $\S 7^{\circ}$ ), tendo especial proteção do Estado. Apresentou-se, ainda, como princípio que assegurará uma vida digna à criança, ao adolescente, ao jovem e ao idoso, sendo dever da família, da sociedade e do próprio Estado (arts. 227 e 230). Ademais, a dignidade humana orienta e protege as relações de trabalho, incluindo o trabalho subordinado exercido por conta alheia, e irradia-se pelos arts. $7^{\circ}$ a 11 da Constituição ao disciplinar os direitos sociais (individuais e coletivos) dos trabalhadores.

Então, a dignidade da pessoa humana - sistematizada por diversos filósofos ao longo da história humana, especialmente por Giovanni Pico della Mirandola como já demonstrado foi incorporada e positivada pelo direito, cristalizou-se nas declarações e pactos internacionais firmados pelos Estados após a segunda metade do século XX e adentrou nas ordens constitucionais de diversos países, principalmente ocidentais, como princípio e valor de maior importância axiológica, unificando os direitos humanos e fundamentais.

Piovesan (2006, p. 31) dispõe acerca do significado e da importância do princípio da dignidade da pessoa humana na ordem constitucional e no âmbito internacional: 
hermenêtica constitucional contemporânea. Consagra-se, assim, a dignidade humana como verdadeiro superprincípio a orientar tanto o direito internacional como o direito interno. [...] Assim, seja no âmbito internacional, seja no âmbito interno (à luz do direito constitucional ocidental), a dignidade da pessoa humana é princípio que unifica e centraliza todo o sistema normativo, assumindo especial prioridade. A dignidade humana simboliza, desse modo, verdadeiro superprincípio constitucional, a norma maior a orientar o constitucionalismo contemporâneo, nas esferas local e global, dotando-lhe de especial racionalidade, unidade e sentido. (grifo nosso)

Analisando a dignidade humana com conceito e valor constitucional, Bartolomei (1987, p. 11 e p. 23) compreende-a como ordem de valor superior (Grundnorm) a orientar a interpretação e a aplicação do direito:

[...] il concetto di "dignità umana" non é già, esclusivamente, una pretesa contro lo Stato, né è un diritto che possa essere esercitato contro altri, ma è un concetto giuridico costituzionale a livello istituzionale con la c.d. pluralità di effetti: a) nessuna "norma" costituzionale puo porsi in contrasto con tale concetto, né il concetto è suscettibile di modificazione mediante revisione costituzionale; b) ogni norma, sia di grado constituzionale, sia di grado subordinato che si ponga in contrasto con detto concetto, va dichiarata inconstituzionale; c) tutta la serie degli atti amministrativi, nonché giurisdizionali non confaceti con il medesimo concetto debbono ritenersi illegittimi. [...] Tale ordine di valori vede come Grundnorm la dignità umana il cui concetto viene a concretare uno di quei principi costituzionale superiori che vale per tutti i campi del diritto: contiene e/o esprime proposizioni precettive regolative di tutte i campi del diritto: da quella d'indirizzo politico a quella legislativa, dalla funzione giurisdizionale a quella ammnistrativa, e cosi via.

Desse modo, a dignidade da pessoa humana é vista como princípio e norma de maior hierarquia axiológica na ordem constitucional brasileira, pois se consubstancia em mandamento nuclear do sistema jurídico pátrio a orientar a interpretação e a concretização dos direitos fundamentais. Portanto, se houver a mitigação do princípio da dignidade humana, estar-se-á ignorando o conteúdo axiológico-valorativo que o fundamenta e, consequentemente, toda a carga histórico-filosófica que o embasa.

Havendo a mitigação do princípio da dignidade humana, ter-se-á a relativização do ser humano, seja em favor do capital nas relações de trabalho quando, por exemplo, há a diminuição de direitos para que se garantam postos de emprego ou quando se implementam políticas públicas que fomentam trabalhos precários e flexíveis que, embora desrespeitem a dignidade do trabalhador e afrontem o direito ao trabalho digno, são justificadas pelos governos como medidas para a diminuição do desemprego etc.; seja, também, em favor da ciência genética no uso de embriões humanos em experiências científicas e na aceitação da prática do aborto no caso de fetos anencéfalos, dentre outros casos. Em tais situações sempre haverá argumentos utilitaristas que justifiquem a relativização da dignidade humana em prol de um "bem maior" que a sociedade 
global de consumo tenha elegido como prioridade em detrimento do respeito ao ser humano.

Não se pode olvidar que a dignidade humana é inerente à própria condição humana, mas se for mitigada, cada pessoa - ser único e insubstituível - será tratada como mercadoria, estando sujeita às relações comerciais e financeiras do sistema capitalista global.

Portanto, após a Segunda Guerra Mundial, a dignidade humana deve ser sempre vista e considerada como o princípio constitucional de maior hierarquia axiológica em face de sua importância ético-jurídica para a humanidade e na qualidade de vetor de proteção aos direitos sociais fundamentais dos cidadãos, especialmente no âmbito da educação e do trabalho, consoante analisado a seguir.

\section{A FUNDAMENTALIDADE DOS DIREITOS SOCIAIS E A VEDAÇÃO AO RETROCESSO SOCIAL NA ORDEM CONSTITUCIONAL BRASILEIRA - REFLEXÕES SOBRE EDUCAÇÃO E TRABALHO}

A partir da compreensão da dignidade humana sob o prisma jusfilosófico, é preciso verificar os termos "Direitos do Homem", "Direitos Humanos" e "Direitos Fundamentais" no contexto da concepção contemporânea dos direitos humanos. Essa discussão foi impulsionada, no século XX, pela doutrina alemã a partir da Constituição ou Lei Fundamental (Grundgesetz) da República Federal Alemã de 1949 ao estabelecer:

[...] uma distinção entre direitos humanos (Menschenrechte) e direitos fundamentais (Grundrechte). Estes últimos são os direitos humanos reconhecidos como tais pelas autoridades, às quais se atribui o poder político de editar normas no interior dos Estados, ou no plano internacional: são os direitos humanos positivados nas Constituições, nas leis e nos tratados internacionais. Segundo essa concepção, os direitos humanos em sentido estrito vigoram como princípios jurídicos não declarados textualmente em diplomas normativos (COMPARATO, 2007, p. 516).

Nesse sentido, Canotilho (2002, p. 393) preleciona:

As expressões "direitos do homem" e "direitos fundamentais" são frequentemente utilizadas como sinónimas. Segundo a sua origem e significado poderíamos distingui-las da seguinte maneira: direitos do homem são direitos válidos para todos os povos e em todos os tempos (dimensão jusnaturalista-universalista); direitos fundamentais são os direitos do homem, jurídico-institucionalmente garantidos e limitados espacio-temporalmente. Os direitos do homem arrancariam da própria natureza humana e daí o seu caráter inviolável, intemporal e universal; os direitos fundamentais seriam os direitos objectivamente vigentes numa ordem jurídica concreta. (grifo do autor)

Acerca dos direitos fundamentais, Ferrajoli (2011, p. 9) também dispõe: 


\begin{abstract}
Proponho uma definição teórica, puramente formal ou estrutural, de "direitos fundamentais": são "direitos fundamentais" todos aqueles direitos subjetivos que dizem respeito universalmente a "todos" os seres humanos enquanto dotados do status de pessoa, ou de cidadão ou de pessoa capaz de agir. Compreendendo por "direito subjetivo" qualquer expectativa positiva (a prestação) ou negativa (a não lesão) vinculada a um sujeito por uma norma jurídica, e por status a condição de um sujeito prevista também esta por uma norma jurídica positiva qual pressuposto da sua idoneidade a ser titular de situações jurídicas e/ou autor de atos que estão em exercício.
\end{abstract}

Então, apesar de os direitos humanos e os fundamentais possuírem diversas definições baseadas na necessidade de seu reconhecimento a fim de garantir a dignidade da pessoa humana, nem sempre eles coincidirão porque nem todos os direitos humanos consagrados no plano internacional foram reconhecidos no plano interno dos Estados na condição de direitos fundamentais.

A Constituição brasileira de 1988, apesar de possuir um texto extremamente avançado com detalhado rol de direitos, caracterizou-se pelo uso da diversidade de termos, destacando-se, ilustrativamente, as seguintes expressões: direitos humanos no art. $4^{\circ}$, inciso II e no art. $5^{\circ}, \S 3^{\circ}$; direitos e garantias fundamentais na epígrafe do Título II e no art. $5^{\circ}, \S 1^{\text {o }}$; direitos e liberdades constitucionais no art. $5^{\circ}$, inciso LXXI e o art. $60, \S 4^{\circ}$, inciso IV dispõe sobre direitos e garantias individuais.

No plano internacional há também o uso variável de expressões para os direitos da pessoa humana. A Declaração Universal dos Direitos Humanos (1948) estabelece no Preâmbulo o necessário respeito aos "direitos do homem", mais à frente cita a "fé nos direitos fundamentais do homem" e o respeito aos "direitos e liberdades fundamentais do homem". A Carta de Direitos Fundamentais da União Europeia (2000) usa o termo "direitos fundamentais" e, por seu turno, a Declaração Americana de Direitos e Deveres do Homem (1948) apresenta as expressões "direitos do homem" e "direitos essenciais do homem".

Em suma, em termos didáticos, os direitos humanos são considerados aqueles resguardados na ordem jurídica internacional enquanto os direitos fundamentais estão previstos no ordenamento constitucional dos Estados, mas a essência ou o fundamento de ambos os direitos é similar: a preservação da dignidade da pessoa humana em sua integralidade porque integra a própria condição humana.

Dessa maneira, os direitos humanos e os fundamentais são considerados indispensáveis e necessários para assegurar a todas as pessoas uma vida digna, livre e mais igualitária, pois se correlacionam com a dignidade humana que é condição intrínseca à própria condição humana. Enfim, a distinção entre direitos humanos e fundamentais, apregoada pelos juristas, possui mais caráter didático porque a essência ou o fundamento desses direitos efetivamente é a mesma, ou seja, visam à proteção da dignidade humana em sua integralidade, havendo diferenciação apenas no grau de concreção positiva: positivação no âmbito do direito constitucional ou do direito internacional dos direitos humanos.

No bojo dos direitos fundamentais estão inseridos os direitos sociais que podem ser 
entendidos como direitos subjetivos. Entretanto, estes "não são meros poderes de agir - como é típico das liberdades públicas de modo geral - mas sim poderes de exigir. São direitos de "crédito"” (FERREIRA FILHO, 1999, p. 49-50). O sujeito passivo dos direitos sociais é o Estado enquanto responsável pelo seu atendimento ou concretização na convivência social; por outro lado, o objeto de tais direitos é tipicamente "uma contraprestação sob a forma da prestação de um serviço. [...] Ou, na impossibilidade de satisfazer o direito por uma prestação direta, uma contrapartida em dinheiro." (FERREIRA FILHO, 1999, p. 51).

Os direitos sociais buscam a implementação da justiça social mediante o fomento integral da pessoa humana e o respeito à sua dignidade, almejando a concretização dos princípios constitucionais da isonomia e de não discriminação. Enfim, os direitos sociais fundamentais são "[...] derechos de la persona concreta y situada, donde, por razones culturales, sociales, fisicas o psíquicas, personas o colectivos se encuentran en desigualdade de condiciones sobre otras. Son los derechos de la mujer, de los niños, de los ancianos, de los minusválidos, de los consumidores." (MARTÍNEZ, 1999, p. 65).

De acordo com Luño (2007, p. 65), os direitos sociais gozam de um regime de proteção jurídica reforçada, justamente em razão de sua fundamentalidade e de seu conteúdo essencial na ordem constitucional, a saber:

La protección de los derechos fundamentales quedaría en entredicho de no hallarse previstos instrumentos normativos de garantía dirigidos a evitar la alteración de su contenido. Los derechos fundamentales son parte del núcleo definitorio de la propia Constitución, cuya permanencia se hace necesaria para mantener y salvaguardar la propia identidad del texto constitucional. De ahí que la mutación del estatuto de los derechos fundamentales no implique una mera mutación parcial de la norma básica, sino que puede entrañar la sustitución de una Constitución por otra. [...].

Logo, os direitos sociais se enquadram na categoria de direitos fundamentais, pois sua fundamentalidade decorre da sua essência ancorada na dignidade da pessoa humana, consoante preceitos analisados à luz do pensamento de Giovanni Pico della Mirandola.

Nesse sentido, o art. $6^{\circ}$ da Constituição estabeleceu que são direitos sociais "a educacão, a saúde, a alimentação, o trabalho a moradia, o transporte, o lazer, a segurança, a previdência social, a proteção à maternidade e à infância, a assistência aos desamparados" (grifo nosso). Tais direitos se enquadram na categoria de fundamentais, gozando de regime de proteção jurídica mais significativa decorrente da força normativa da Constituição brasileira e do caráter vinculativo e obrigatório de suas disposições (regras ou princípios) ${ }^{5}$. Portanto, os direitos previstos no art. $6^{\circ}$

5 Segundo Hesse (1983, p. 74), “[...] resulta de fundamental importancia para la preservación y la consolidación de la fuerza normativa de la Constitución la interpretación constitucional. Esta se encuentra sometida al mandato de la realización óptima de la norma. Que dicho mandato no puede ser cumplido con los medios de la subsunción lógica o de la construcción conceptual es algo que se comprende por sí mismo. Si el Derecho, y en especial el Derecho constitucional, ve condicionada su eficacia por las concretas relaciones sociales, la interpretación no podrá entonces ignorarlas. Tendrá que apreciar estos condicionamientos y ponerlos en relación con el contenido normativo del precepto constitucional. La interpretación correcta será aquella que, bajo las condiciones concretas de la situación 
se desdobram ao longo do texto constitucional em outros preceitos normativos, contribuindo para minimizar as desigualdades sociais e reforçando o vínculo da cidadania, pois cidadão é "aquele que detém direitos civis (liberdades individuais) e políticos (participação política), mas também direitos sociais (trabalho, educação, habitação, saúde e prestações sociais em tempo de vulnerabilidade). O vínculo da cidadania, sob esse ponto de vista, materializa-se em duplo sentido." (MARTÍNEZ, 1999, p. 65, tradução nossa).

$\mathrm{Na}$ ordem jurídica brasileira, a Constituição de 1988 inaugurou novos contornos para a concepção de cidadania, incluindo-a dentre os princípios e direitos fundamentais (art. $1^{\mathrm{o}}$, II da $\mathrm{CF}$ ) a fim de conceder a máxima efetividade aos direitos sociais fundamentais (art. $5^{\circ}, \S 1^{\circ} \mathrm{da} C F$ ). $\mathrm{Na}$ contemporaneidade, há ainda outras dimensões a balizar a cidadania, pois se está diante de direitos de titularidade difusa e universal que requerem a inclusão de pessoas com particularidades e diversidades culturais, étnicas etc. Logo, faz-se necessário o reconhecimento de uma "cidadania multicultural" na medida em que o cidadão poderá exercer várias cidadanias (locais, regionais, nacionais etc.) no âmbito de diferentes comunidades políticas a que pertença (SMANIO, 2009, p. 17).

Nesse contexto, o princípio da proibição de retrocesso social está umbilicalmente relacionado ao respeito à cidadania e à garantia dos direitos fundamentais já conquistados pelos cidadãos brasileiros, decorrendo, principalmente, de princípios como o do Estado Democrático e Social de Direito, o da dignidade da pessoa humana, o da máxima eficácia e efetividade das normas definidoras de direitos fundamentais e o da segurança jurídica, conforme Sarlet (2006, p. 320-321) também preleciona:

[...] verifica-se que a proibição de retrocesso, mesmo na acepção mais restrita aqui enfocada, também resulta [...] diretamente do princípio da maximização da eficácia de (todas) as normas de direitos fundamentais. Por via de conseqüência, o art. $5^{\circ}, \S 1^{\circ}$, da nossa Constituição, impõe a proteção efetiva dos direitos fundamentais não apenas contra a atuação do poder de reforma constitucional (em combinação com o art. 60, que dispõe a respeito dos limites formais e materiais às emendas constitucionais), mas também contra o legislador ordinário e os demais órgãos estatais, já que medidas administrativas e decisões jurisdicionais também podem atentar contra a segurança jurídica e a proteção de confiança.

Desse modo, o legislador ordinário, na elaboração das normas infraconstitucionais, e os órgãos públicos, na concretização dessas normas, não podem restringir ou suprimir os direitos fundamentais, principalmente sociais como é o caso da educação e do trabalho, havendo, em nível constitucional, limites ao poder de livremente reformar a Constituição, sobretudo no âmbito dos direitos fundamentais (art. 60, $\S 4^{\circ}$, inciso IV).

dada, realice de forma óptima el sentido de la regulación normativa. Ello implica el que, con el cambio de las relaciones de hecho, la interpretación de la Constitución también pueda cambiar, tenga incluso que cambiar. Pero al mismo tiempo en la vinculación de toda interpretación constitucional al sentido de la regla normativa radica el límite a cualquier interpretación constitucional por medio de la interpretación. La finalidad (telos) del precepto constitucional y su clara voluntad normativa no deben ser sacrificados al cambio de situación. Cuando el sentido de una regulación normativa no puede ser realizado en una realidad modificada sólo queda la posibilidad de la revisión constitucional". 
Entretanto, a realidade fática brasileira se mostra bastante distante da efetivação desses preceitos constitucionais porque se vivencia no país nos últimos anos o aprofundamento do processo de desconstrução dos direitos sociais, ameaçando as mais diferentes áreas, como a educação em que o Estado está contratando professores voluntários temporários no ensino público superior, principalmente nas universidades públicas federais. Essa modalidade de trabalho não gera vínculo empregatício e nem obrigações trabalhistas e previdenciárias, trazendo profunda insegurança jurídica aos trabalhadores.

A Resolução $n^{0}$ 02, de 11 de setembro de 2018, do Conselho Nacional de Educação do Ministério da Educação e Cultura (MEC) - publicada no DOU em 12 de setembro de 2018, seção 01, p. 147 - instituiu diretrizes para o trabalho voluntário na educação básica e superior que já vinha sendo utilizado nas universidades públicas federais com fulcro na Lei ${ }^{\circ}$ 9.608/1998, precarizando o labor intelectual dos professores e, por via reflexa, desconstruindo o direito fundamental à educação (arts. $6^{\circ}$ e 205 da CF).

Segundo prevê o art. $1^{\text {o }}$ da Lei $\mathrm{n}^{\circ}$ 9.608/1998, considera-se serviço voluntário, a atividade não remunerada prestada por pessoa física a entidade pública de qualquer natureza ou a instituição privada de fins não lucrativos que tenha objetivos cívicos, culturais, educacionais, científicos, recreativos ou de assistência à pessoa. O serviço voluntário não gera vínculo empregatício, nem obrigação de natureza trabalhista previdenciária ou afim.

O serviço voluntário será exercido mediante a celebração de termo de adesão entre a entidade, pública ou privada, e o prestador do serviço voluntário, dele devendo constar o objeto e as condições de seu exercício (art. $2^{\circ}$ da Lei $n^{\circ}$ 9.608/1998). O prestador do serviço voluntário poderá ser ressarcido pelas despesas que comprovadamente realizar no desempenho das atividades voluntárias as quais deverão estar expressamente autorizadas pela entidade a que for prestado o serviço voluntário (art. $3^{\circ}$ da Lei no 9.608/1998).

A adoção da figura do professor voluntário em universidades públicas federais se respalda na Lei $n^{\circ}$ 9.608/1998, em resoluções específicas de cada instituição de ensino superior e agora está chancelada pelo MEC na Resolução $n^{\circ}$ 02/2018 ao permitir a utilização de estudantes no desenvolvimento de atividades pedagógicas e educacionais que eram, até então, desenvolvidas pelos docentes efetivos.

A situação é caótica e deveras preocupante, pois, além da questão da precarização do trabalho intelectual desses profissionais, ocorre também a contratação pelo Estado de professores voluntários, substituindo pessoal permanente, para a prestação de serviços sem a realização do concurso público. Tal fato viola o art. 37, caput e inciso II da Constituição, pois o concurso é a forma mais democrática de acesso de pessoas aos cargos públicos em observância ao princípio da isonomia (art. $5^{\circ}$, caput da CF).

Somente poderia ocorrer exceção à regra geral do concurso público em casos excepcionais, autorizados no art. 37, IX da Constituição, havendo a previsão dos casos permitidos (numerus clausus) na Lei $\mathrm{n}^{\circ} 8.745 / 1993^{6}$. Nestes casos, haveria a contratação de trabalhadores por tempo 
determinado e sem concurso público para atender a necessidade temporária de excepcional interesse público, ou seja, foram estabelecidas exceções restritivas ao acesso a cargos, empregos e funções públicas em consonância com os princípios constitucionais da legalidade, impessoalidade, moralidade, publicidade e eficiência (art. 37, caput da CF), norteadores dos atos do Estado no exercício da função administrativa.

No caso da docência, o art. $2^{\circ}$ da Lei $n^{\circ} 8.745 / 1993$ autoriza a admissão de professor substituto e professor visitante, bem como de professor e pesquisador visitante estrangeiro (incisos IV e V, respectivamente) para suprir a necessidade temporária de excepcional interesse público. O parágrafo $1^{\circ}$ do art. $2^{\circ}$ da Lei ${ }^{\circ} 8.745 / 1993$ aponta que a contratação de professor substituto (IV) somente poderá ocorrer para suprir a falta de professor efetivo em razão de: vacância do cargo; afastamento ou licença, na forma do regulamento e nomeação para ocupar cargo de direção de reitor, vice-reitor, pró-reitor e diretor de campus. O número total de professores contratados nesta modalidade não poderá ultrapassar vinte por cento do total de docentes efetivos em exercício na instituição federal de ensino (art. $2^{\circ}, \S 2^{\circ}$ do da Lei ${ }^{\circ}$ 8.745/1993).

O parágrafo $5^{\circ}$ do art. $2^{\circ}$ da Lei $n^{\circ} 8.745 / 1993$ estabelece que a contratação de professor visitante e de professor visitante estrangeiro (IV e V, respectivamente) tem por objetivo: apoiar a execução dos programas de pós-graduação stricto sensu; contribuir para o aprimoramento de programas de ensino, pesquisa e extensão; contribuir para a execução de programas de capacitação docente e viabilizar o intercâmbio científico e tecnológico.

Desse modo, no caso de professores não efetivos, a Lei ${ }^{\circ}$ 8.745/1993 apresenta rigorosamente os casos permitidos para atender a necessidade temporária de excepcional interesse público. Entretanto, o governo federal está burlando a aplicação desta norma, permitindo a contratação de professores voluntários (não efetivos) em situações que extrapolam os limites jurídicos disciplinados na Lei $\mathrm{n}^{\circ} 8.745 / 1993$, precarizando o labor intelectual dos professores nas universidades públicas federais. Por via reflexa, não há efetividade aos direitos fundamentais à educação e ao trabalho digno os quais estão sendo dilacerados no Brasil.

No âmbito laboral, vislumbra-se nas últimas décadas que o Direito do Trabalho brasileiro sofreu ataques de várias frentes, no contexto nacional e internacional, que alardearam que a Consolidação das Leis do Trabalho (CLT) estaria ultrapassada e engessaria o desenvolvimento econômico, a geração de empregos e a competitividade das empresas. Tais discursos flexibilizadores, de cunho neoliberal, são falaciosos, pois objetivaram apenas o desmonte da legislação laboral brasileira, que goza de proteção constitucional, bem como a extinção da Justiça do Trabalho que promove a efetivação da justiça social, sendo especializada na resolução das lides trabalhistas, conforme competência material prevista no art. 114 da Constituição.

Nesse contexto, foi aprovada a Lei $\mathrm{n}^{\circ}$ 13.467/2017, chamada de "reforma" trabalhista, que impactou no Direito Material e Processual do Trabalho, esgarçando o sistema juslaboral de proteção aos trabalhadores. Tal situação é crítica porque a desproteção dos obreiros é evidente pelo conteúdo da maioria das alterações realizadas por tal lei no texto celetista e seu impacto na geração

interesse público, nos termos do inciso IX do art. 37 da Constituição Federal e dá outras providências. 
de empregos mostrou-se ínfimo até o presente momento, pois há no Brasil mais de doze milhões de pessoas desempregadas na atualidade.

À título exemplificativo, no Direito Individual do Trabalho, destaca-se o contrato de trabalho intermitente (art. $443, \S 3^{\circ}$ da CLT) que possui jornada de trabalho e salário variáveis, compreendendo períodos de atividades e inatividades não previamente estabelecidos entre o empregado e o empregador - independentemente do ramo da atividade econômica -, causando total incerteza aos obreiros se o seu trabalho será requisitado ou, ainda, o valor efetivo da remuneração recebida ao final do mês, violando os princípios trabalhistas da continuidade da relação de emprego e da proteção laboral (princípio tuitivo ou tutelar).

Introduziu-se também na norma celetista a tarifação do dano extrapatrimonial (art. 223-A e seguintes da CLT), impondo faixas de reparação dos danos extrapatrimoniais segundo a natureza e a gradação da lesão sofrida (leve, média, grave e gravíssima) para as indenizações devidas aos empregados, tendo por base o salário contratual. Tal preceito normativo viola o princípio constitucional da isonomia e o direito à igualdade (art. $5^{\circ}$, caput da $\mathrm{CF}$ ), pois impõe parâmetros diferenciados de indenização aos trabalhadores com base na sua remuneração, algo inexistente no Direito Civil brasileiro para outros sujeitos de direito.

Outra modificação decorrente da "reforma" foi o termo anual de quitação do contrato de trabalho (art. 507-B da CLT) que facultou aos empregados e empregadores, na vigência ou não do contrato de trabalho, dar quitação anual das obrigações trabalhistas devidas. É notório que os empregados, na condição de parte hipossuficiente da relação empregatícia, serão compelidos à assinatura anual deste termo de quitação das verbas trabalhistas a fim de manterem seus postos de trabalho, principalmente em razão do número expressivo de desempregados atualmente existente no país, ainda que discordem dos valores a serem quitados ou na pendência de obrigações trabalhistas não pagas. Logo, caberá ao empregado hipossuficiente a prova da ocorrência de possível erro, dolo ou coação na assinatura deste termo de quitação, o que estimulará a proliferação de abusos e práticas ilícitas por parte daqueles empregadores que agem de má-fé.

No campo do Direito Coletivo do Trabalho, a "reforma" promoveu o enfraquecimento do sindicato, muito ao contrário do que foi alardeado, pois tornou facultativa a cobrança da contribuição sindical sem outra contrapartida financeira (art. 579, CLT); permitiu a realização de banco de horas, prorrogação e compensação de jornada (art. 59, CLT) e jornada de trabalho 12x36 (art. 59-A, CLT) por acordo individual, esvaziamento a atuação sindical; extinguiu a homologação sindical das rescisões contratuais de empregados com mais de um ano de vigência de contrato de trabalho pela revogação do $\S 1^{\circ}$ do art. 477 , CLT; dispensou a autorização prévia do sindicato para as dispensas imotivadas individuais, plúrimas ou coletivas (art. 477-A, CLT), dentre outras situações.

$\mathrm{Na}$ seara do processo do trabalho, dentre as várias mudanças realizadas na norma consolidada pela "reforma", cita-se exemplificativamente a inclusão do $\S 4^{\circ}$ no art. 790 da CLT exigindo a comprovação da hipossuficiência do trabalhador para a concessão da gratuidade dos atos processuais, ou seja, o obreiro deverá apresentar muito mais do que a simples declaração. No 
caso de pessoa natural, a hipossuficiência é presumida no art. $99, \S 3^{\circ}$ do CPC cuja aplicação deve ser subsidiária no processo do trabalho (art. 15 do CPC e art. 769 da CLT). Esta imposição para se comprovar a hipossuficiência dificulta ao trabalhador o pleno exercício do seu direito fundamental de acesso à tutela jurisdicional justa e efetiva garantida no texto constitucional (art. $5^{\circ}, \mathrm{XXXV}$ e LXXIV da CF).

Em relação aos honorários periciais, a alteração da parte final do caput do art. 790-B da CLT exigiu o pagamento dos honorários periciais pela parte sucumbente na pretensão objeto da perícia mesmo na condição de ser beneficiária da gratuidade dos atos processuais - o que se aplicava a muitos trabalhadores na condição de reclamantes -, violando o princípio da inafastabilidade da prestação jurisdicional. $\mathrm{O} \S 4^{\circ}$ do art. 790-B da CLT autorizou, ainda, a utilização de créditos de natureza alimentar obtidos pelo trabalhador na ação em curso ou noutro processo (trabalhista ou não) para o pagamento dos honorários periciais. Este parágrafo é inconstitucional ao violar direitos fundamentais dos trabalhadores, em especial o direito à vida e à saúde no meio ambiente do trabalho, o devido processo legal e o direito de acesso à prestação jurisdicional justa e efetiva no âmbito individual ou coletivo.

Por seu turno, o art. 878 da CLT passou a exigir que a execução trabalhista seja iniciada, em regra, por provocação do exequente, sendo de ofício quando as partes estiverem no exercício do jus postulandi (art. 791, CLT) e no caso das contribuições sociais oriundas das sentenças proferidas na Justiça do Trabalho e dos acordos por ela homologados (art. 876, parágrafo único, CLT). Criam-se, assim, procedimentos distintos para o exequente-trabalhador e para a exequenteFazenda Pública em detrimento daquele que terá cerceado seu pleno exercício de acesso à tutela jurisdicional justa e efetiva.

Em síntese, as alterações realizadas pela "reforma" trabalhista na Consolidação das Leis do Trabalho, em sua maioria expressiva, objetivaram a desconstrução dos direitos sociais laborais conquistados pelos cidadãos nos últimos séculos.

Desse modo, a realidade demonstra que se vivencia no Brasil etapa sombria de desmonte da estrutura de bem-estar social e de direitos sociais, principalmente na educação e no trabalho consoante apontado, que vem sendo empreendida sob os auspícios da globalização econômica neoliberal que está esvaziando e anulando a dignidade da pessoa humana, apregoada desde Giovanni Pico della Mirandola, em prol de interesses das elites econômicas e políticas que estão no poder.

\section{CONCLUSÃO}

O ser humano "criou" o direito, convertendo as necessidades sociais e políticas em normas cogentes de conduta e convivência social, disciplinando suas relações na vida em comunidade. No decorrer da história e da civilização humanas evoluiu a concepção da dignidade da pessoa humana como indissociável do direito, pois ela não esteve sempre presente nas leis escritas para todos os povos e Estados, mas foi construída e reconstruída permanentemente no convívio social na 
condição de valor inerente à condição humana.

Sob esse prisma, verificou-se a importância do pensamento de Giovanni Pico della Mirandola, no âmbito do humanismo renascentista do século XV, ao apreender o homem como o milagre da criação divina, a centralidade do mundo e o mediador das realidades terrena, celeste e divina, guiando-se por seu livre arbítrio, semeando-se, assim, a ideia de que a pessoa seria o sujeito central do mundo, da polis e da communitas.

Giovanni Pico della Mirandola desenvolveu a ideia de que o homem pode ascender na cadeia das criaturas pelo exercício de suas capacidades intelectuais o que seria a garantia de dignidade da existência humana na vida terrestre. Assim, a própria dignidade humana residiria na afirmação de que somente os seres humanos poderiam mudar a si mesmos pelo seu livre arbítrio, tendo responsabilidade pela vida que tinham. Revela-se, assim, a valorização do homem como soberano de si mesmo, orientado por sua razão e livre arbítrio, como a centralidade do mundo, sendo a dignidade uma condição intrínseca à sua natureza de "camaleão", multiforme e mutável.

As considerações deste filósofo renascentista contribuíram para a consolidação da visão antropocêntrica do mundo. Entretanto, a partir do século XIX, com o desenvolvimento do capitalismo industrial e financeiro, houve a agudização do individualismo como referencial adotado nas sociedades, proporcionando a mitigação dessa dignidade da pessoa humana.

Entretanto, Immanuel Kant entendeu que a ação humana deveria se limitar por primados éticos, que convencionou chamar de imperativos categóricos, tendo como referência a relação EuOutro, pois o homem não poderia ser visto no mundo de forma isolada como senhor absoluto de sua vontade e liberdade, mas, ao invés disso, estaria em constante inter-relação e interdependência com seu semelhante, devendo nortear sua ação por princípios éticos e racionais que considerassem a pessoa humana como um fim em si mesma.

Assim, a dignidade da pessoa humana cristalizou-se nas declarações, pactos e convenções internacionais firmados pelos Estados, sobretudo após a segunda metade do século XX, sendo incorporada, posteriormente, nas ordens constitucionais de diversos países, principalmente ocidentais, inclusive no Brasil, como princípio e valor de maior hierarquia axiológica a fim de nortear a interpretação e aplicação do direito, em especial dos direitos humanos e fundamentais.

$\mathrm{Na}$ Constituição brasileira de 1988, a dignidade humana foi consagrada ao longo de todo o texto constitucional, com ênfase no art. $1^{\circ}$, inciso III como fundamento do Estado Democrático de Direito; na condição de finalidade precípua da ordem econômica (art. 170) e da ordem social (art. 193); bem como orientando e protegendo as relações de trabalho nos contornos evidenciados nos arts. $7^{\circ}$ a 11 da Constituição.

Portanto, o respeito à dignidade da pessoa humana permite a concretização dos direitos fundamentais dos cidadãos, principalmente dos direitos sociais, que se desdobram ao longo do texto constitucional em outros preceitos normativos como a educação e o trabalho, sendo compreendidos como indispensáveis e necessários para assegurar a todas as pessoas uma existência digna, livre e igual, minimizando as desigualdades sociais e reforçando o vínculo da cidadania.

Porém, o Congresso brasileiro e o governo federal promoveram visível afronta à 
fundamentalidade dos direitos sociais e ao princípio de vedação ao retrocesso social ao permitirem a aprovação da "reforma" trabalhista cujas "novidades" inseridas no texto celetista, em sua maioria expressiva, objetivaram apenas a desconstrução dos direitos trabalhistas, prevalecendo os interesses da globalização neoliberal e excludente que transforma as pessoas em mercadorias.

Esta "nova" desordem capitalista global impulsiona a desconstrução dos direitos sociais laborais, promovendo a generalização da flexibilidade laboral com a crescente precarização do trabalho humano e das condições de trabalho para que as empresas se mantenham competitivas, em nível interno e internacional, em detrimento da dignidade humana do trabalhador, comprometendo a efetividade social dos direitos trabalhistas e, consequentemente, a busca da justiça social.

$\mathrm{Na}$ seara da educação, destacou-se o uso indiscriminado de professores voluntários no ensino superior, principalmente nas universidades públicas federais, evidenciando que a educação brasileira não está sendo considerada como projeto de Estado, mas como projeto de um governo de cunho neoliberal que, mediante ações e políticas públicas restritivas, está promovendo o retrocesso social e a desconstrução dos direitos fundamentais sociais. A situação é preocupante, pois, além da questão da precarização do trabalho intelectual desses profissionais, está ocorrendo a contratação de professores voluntários, substituindo pessoal permanente, para a prestação de serviços sem a realização do concurso público em afronta ao art. 37, caput e II da Constituição, pois o concurso é a forma mais democrática e isonômica de acesso de pessoas aos cargos públicos (art. $5^{\circ}$, caput da CF).

Chanceladas pelo Congresso Nacional brasileiro, tais situações representam profundo retrocesso social ao Estado Democrático de Direito, desconstruindo direitos sociais fundamentais (educação e trabalho), colocando o país no caminho inverso ao que propõe a Constituição ao estabelecer que, dentre os objetivos do Estado brasileiro, está a construção de uma sociedade justa e solidária com a erradicação da pobreza, marginalização e redução das desigualdades sociais e regionais (art. $3^{\circ}$, I e III da CF).

Então, está prevalecendo atualmente o jogo de interesses de elites econômicas e políticas que simplesmente está "rasgando" os compromissos assumidos pelo Brasil perante a Organização Internacional do Trabalho (OIT) e a comunidade internacional, bem como "esfacelando" os preceitos resguardados na Constituição Cidadã de 1988.

Contrariamente a esse "estado de coisas", todo o ser humano, em especial o trabalhador, deveria sempre ser visto como um fim em si mesmo, possuidor de um valor (a sua dignidade) e não como mera mercadoria descartável, sendo-lhe garantidas políticas públicas que promovessem sua reintegração social na comunidade e sua recolocação profissional no mercado de trabalho, contribuindo para a concretização dos direitos sociais fundamentais ao trabalho digno e à educação superior pública, gratuita e de qualidade, pois “[...] o comportamento ético é bom ou é mau conforme ele seja bom ou mau para os laços de nossa irmandade natural. Só pode ser bom, à luz da ética quântica, o comportamento que trata o próximo como irmão.” (TELLES JUNIOR, 2014, p. 280).

Essa interpretação compatibiliza, no âmbito do Constitucionalismo do século XXI, os 
fundamentos do Estado Democrático e Social de Direito - a cidadania, a dignidade da pessoa humana e os valores sociais do trabalho - com o objetivo de se construir uma sociedade fraterna e pluralista, reduzindo-se as desigualdades sociais, minimizando a pobreza e a marginalização sociais, nos termos do pensamento de Giovanni Pico della Mirandola - exarado na Oratio de Hominis Dignitate - que deve ser revisitado em tempos tão sombrios de desconstrução dos direitos sociais fundamentais dos cidadãos brasileiros.

\section{REFERÊNCIAS}

ABBAGNANO, Nicola. Dicionário de filosofia. Tradução de Ivone Castilho Benedetti. 5. ed. São Paulo: Martins Fontes, 2007.

BARTOLOMEI, Franco. La dignitá umana come concetto e valore costituzionale. Torino: Italia, G. Giappichelli Editore, 1987.

CANOTILHO, José Joaquim Gomes. Direito constitucional e teoria da constituição, 6. ed., Coimbra: Livraria Almedina, 2002.

PROFETAS: Oséias, Amós, Isaías, Miquéias, Daniel, Jeremias, Ezequiel, Jonas, Zacarias, Revista das Religiões, São Paulo, v. 1, 2006. Coleção Grandes Heróis Bíblicos

COMPARATO, Fábio Konder. A afirmação histórica dos direitos humanos. São Paulo: Saraiva, 2007a.

COMPARATO, Fábio Konder. Ética: direito, moral e religião no mundo moderno. 5. ed. São Paulo: Companhia das Letras, 2007b.

FERRAJOLI, Luigi. Por uma teoria dos direitos e dos bens fundamentais. Tradução de Alexandre Salim, Alfredo Copetti Neto, Daniela Cadermatori, Hermes Zaneti Júnior e Sérgio Cadermatori. Porto Alegre: Livraria do Advogado Editora, 2011.

FERREIRA FILHO, Manoel Gonçalves. Direitos humanos fundamentais. São Paulo: Saraiva, 1999.

HESSE, Konrad. Escritos de derecho constitucional (selección). Madrid: Centro de Estúdios Constitucionales, 1983.

KANT, Immanuel. Fundamentação da metafísica dos costumes e outros escritos. Tradução de Leopoldo Holzbach. São Paulo: Martin Claret, 2008.

LAFER, Celso. A reconstrução dos direitos humanos: um diálogo com o pensamento de Hannah Arendt. São Paulo: Companhia das Letras, 2006.

LOIA, Luís. Acerca do pensamento de Giovanni Pico della Mirandola. In: MIRANDOLLA, Giovanni Pico della. Discurso sobre a dignidade do homem (Oratio de Hominis Dignitate). Tradução de Maria de Lurdes Sirgato Ganho. Lisboa: Edições 70, 2006. p. 7-39

LUÑO, Antonio Enrique Perez. Los derechos fundamentales. 9. ed. Madrid: Tecnos, 2007. MARTÍNEZ, Gregorio Peces-Barba. Derechos sociales y positivismo jurídico: escritos de 
filosofia jurídica y política. Cuadernos Bartolome de Las Casas, Madrid, n. 11, 1999.

PIOVESAN, Flávia. Direitos humanos e o direito constitucional internacional. 7. ed. São Paulo: Saraiva, 2006.

SMANIO, Gianpaolo Poggio. Dimensões da cidadania, novos direitos e proteção da cidadania. Revista da Escola Superior do Ministério Público, São Paulo, ano 2, p. 13-23, jan./jun. 2009.

SARLET, Ingo Wolfgang. Dignidade da pessoa humana e direitos fundamentais na Constituição de 1988. 5. ed. Porto Alegre: Livraria do Advogado, 2007.

SARLET, Ingo Wolfgang. Proibição de retrocesso, dignidade da pessoa humana e direitos sociais: manifestação de um constitucionalismo dirigente possível. In: BONAVIDES, Paulo; LIMA, Francisco Gérson Marques de; BEDÊ, Fayga Silveira. Constituição e democracia: estudos em homenagem ao Prof. J. J. Gomes Canotilho. São Paulo: Malheiros Editores, 2006. p. 291-355.

SILVA, De Plácido e. Vocabulário jurídico. 26. ed. Rio de Janeiro: Forense, 2005.

TELLES JUNIOR, Goffredo. Ética: do mundo da célula ao mundo dos valores. 3. ed. São Paulo: Saraiva, 2014.

Como citar: MARTINS, Juliane Caravieri. Revisitando a dignidade da pessoa humana em tempos de desconstrução de direitos sociais fundamentais (educação e trabalho): contributo de Giovanni Pico Della Mirandola. Revista do Direito Público, Londrina, v. 14, n. 3, p. 64-86, dez. 2019. DOI: 10.5433/24157-108104-1.2019v14n3p. 64. ISSN: 1980-511X

Recebido em: 18/07/2017

Aprovado em: 20/05/2019 